\title{
ACERCA DE LA (IM)POSIBILIDAD DE UN DICCIONARIO SOBRE DERRIDA
}

\section{Comentario a Morgan Wortham, Simon. The Derrida Dictionary, Continuum, Londres/Nueva York, 2010.}

\section{Pablo Cerone*}

Los diccionarios son artefactos literarios complejos. Generalmente se espera de ellos que, empleando un mínimo de recursos, brinden el máximo de información posible de la manera más diáfana y contundente que se pueda concebir. De ese modo el diccionario es percibido como un instrumento al que se recurre para evacuar dudas rápidamente, prosiguiendo con la tarea interrumpida una vez finalizada la consulta. Es decir, según las convenciones, los diccionarios son textos sobre los que casi no es lícito demorarse, y frente a los cuales no se suele cuestionar la certeza de sus enunciaciones: la velocidad que permiten y la autoridad que emanan son los rasgos más distintivos que los diccionarios poseen.

Resulta difícil, entonces, que un lector de un diccionario critique el anhelo de sistematización que estos textos suponen, puesto que el orden alfabético ya dibuja una linealidad a la que se siente "natural". Además el hecho de que cada letra esté ubicada siempre detrás de la misma otra favorece la mecanización del proceso de búsqueda, lo que contribuye a generar una imagen donde todo no sólo goza de su lugar particular, sino que además permanece gozosamente en él. Son especialmente aquellos lectores formados en el seno de una cultura logocéntrica quienes abordan de ese modo la lectura de un diccionario.

\footnotetext{
* Licenciado en Filosofía por la Universidad Nacional de Tucumán en el año 2009 con la tesina "El motivo de la escritura en Jacques Derrida". Profesor Adjunto de Lógica en la Universidad de San Pablo, Tucumán. Dirección electrónica: pablocerone@hotmail.com
} 
Ahora bien, es sabido que Jacques Derrida (1930-2004) fue un implacable fustigador del logocentrismo, especialmente de aquel que, morando en el corazón de la filosofía, paulatinamente fue desbordándose hacia los demás espacios discursivos. A raíz de ello, toda su obra (y toda su vida, $\tan$ forzosamente ligada a ella) puede ser interpretada como un trabajo que desafió los órdenes, los equilibrios y las moderaciones de la cultura logocéntrica, pero que no necesariamente pretendió destruirla.

Esto explica por qué razón el pensamiento derridiano nunca se jactó de ser hostil a su codificación bajo el formato diccionario, y por qué causa, a su vez, siempre reconvirtió esa práctica. Lo que decimos se comprende mejor si se recuerda que Geoffrey Bennington, en el año 1991, publicó la famosa Derribase -una suerte de base de datos acerca de la deconstrucción-, a la cual el propio Jacques Derrida impugnó a través del autobiográfico Circonfesión. Lo que ambos autores habían conjurado en aquella oportunidad era ejecutar una serie de cortes y recortes sobre el corpus derridiano, con la esperanza de mostrarles a los hipotéticos lectores el compromiso de coherencia y consistencia siempre presente en los diversos esfuerzos intelectuales de Derrida, al mismo tiempo que los instaban a dudar de toda seguridad contextual que pudiese someter y reducir a la escritura derridiana a una serie de fórmulas y eslóganes. A casi veinte años de aquella aventura, Simon Morgan Wortham la evoca y la utiliza para orientar su propia empresa.

En efecto, Morgan Wortham se ha propuesto elaborar un diccionario sobre la obra de Jacques Derrida intentando eludir los prejuicios más comunes que acarrean los lectores logocéntricos a la hora de aproximarse a un texto de este tipo, pero sin por ello adoptar estrategias abruptas o salidas fáciles. Su tarea es más bien sutil, pues consiste siguiendo el ejemplo de Bennington y Derrida- en circular dentro de las convenciones más comunes que rodean al mundo de los diccionarios, al mismo tiempo que busca subvertir los parámetros más tradicionales que usualmente dictan las coordenadas del género.

La postura de Morgan Wortham no es caprichosa, sino que nace de la pretensión de conservar lo más fulgurante de la obra de Derrida. Es así 
que The Derrida Dictionary parte de una premisa curiosa: intentar sistematizar -al menos según un orden alfabético- a un pensamiento que, deliberadamente, ha buscado esquivar su propia sistematización. Sin embargo, al recorrer las páginas del libro, se hace evidente que Morgan Wortham elige cuidadosamente el camino para incumplir esa tarea, proponiendo en su lugar una perspectiva más acorde a la construcción derridiana de la filosofía.

En este punto es posible afirmar que la labor de Morgan Wortham es solidaria con la postura del propio Derrida de plantear a lo producido por el filósofo francés como si fuese una red de reflexiones (quizás la palabra más adecuada sería "deconstrucciones"), que tendrían por objetivo último el de señalar que todo aquello que pueda ser identificado como "fundamento" -y que, por ende, favorezca la construcción de un sistema- ha sido impuesto por un acto violento y arbitrario, que en realidad sólo ha terminado lograr impulsar una serie de exclusiones que nunca alcanzan a ser totales. De allí se deduce que, para Derrida, ningún sistema puede ser completo y autosuficiente, ya que, por el contrario, éstos siempre dependerían de elementos no-sistematizables que producirían y mantendrían de facto (mas no de jure) la misma posibilidad del sistema.

En líneas generales, cabe reconocer que lo que el autor de The Derrida Dictionary se propone es cartografiar la producción textual derridiana, indicando, fundamentalmente, cuál es el lugar privilegiado de los diversos componentes genealógicos en los escritos de Derrida y cómo son las relaciones posibles que se pueden trazar entre una serie de términos claves (a los que, ante la prohibición de considerarlos "conceptos", se los debería denominar, tal vez, "motivos") que abundan en la obra del filósofo francés. El resto del diccionario está dedicado a reunir una serie de ensayículos breves, construidos con delicadeza y precisión, que invitan a ser atravesados con paciencia para comprender cuál fue la instancia de producción y cuáles son los desarrollos sugeridos de cada texto leído y comentado por Morgan Wortham.

Debido a ello no es errado sostener que The Derrida Dictionary puede ser tomado como una antología de piezas textuales derridianas que su autor 
selecciona, para avanzar luego en su exposición procurando no extenderse a lo largo de demasiadas páginas. Junto a esos ensayículos, como ya se ha señalado más arriba, se encuentran las entradas dedicadas a la constelación de motivos derridianos, que la mayoría de las veces se posicionan como cadenas de significación, en donde una embestida deconstructiva o diseminante se vincula con otra que se le asemeja mucho pero que difiere bastante (a modo de ejemplo se podrían tomar los desplazamientos de motivos como los de "archi-escritura", "huella", "suplemento", "différance", etc. que remiten, aunque con diversos contrastes, al mismo proceso de elaboración metafilosófico).

En cuanto a la construcción genealógica de Derrida, aparecen con entradas propias los nombres de Aristóteles, Kant, Rousseau, Hegel, Husserl, Heidegger, Freud, Bataille, Lévinas, de Man, etc., pero sin destacar más que sus fechas de nacimiento y muerte, su caracterización como autor, y el título del trabajo de Derrida referido en el diccionario en el cual su abordaje es más notorio.

Finalmente se puede agregar algo que cualquier lector de The Derrida Dictionary notará de inmediato al recorrer el libro: cada entrada es pródiga en palabras resaltadas. Evidentemente ello sugiere que esa palabra (ya sea la denominación de un motivo, el nombre de un autor influyente o afluente, o el título de una entrevista, ensayo o libro de Derrida) tiene su propio espacio en el diccionario. $\mathrm{Y}$, dado que el pensamiento y la práctica derridiana desaconsejan confiarse en las jerarquizaciones rigurosas, dicha multiplicidad de palabras resaltadas bien podría funcionar como una invitación a considerar al diccionario como un hipertexto que le facilite al lector la entrada curiosa y la salida alertada de los escritos, argumentos, terminologías, lecturas e ideas que constituyen el universo de Jacques Derrida. 